\title{
Some Studies on Yeast.
}

\author{
BY
}

HORACE T. BROWN, F.R.S.

With eight Figures in the Text.

\section{PART I.}

\section{The Relation of Cell-Reproduction to the Supply OF FREE OXYGEN.}

\section{$T$}

$\mathrm{HE}$ rate of increase of living cells undergoing division in an environment suited to their growth is influenced by so many factors that any attempt to analyse them, and to demonstrate the limitations which they severally impose on cell-increase, becomes exceedingly difficult if attention is confined to multicellular organisms.

The problem can be much simplified if we consider a unicellular organism such as ordinary yeast, for in such a case we have not only the power of controlling the external conditions with comparative ease, but also a ready means of estimating the actual cell-increase by direct counting of the cells. Moreover, there is the further advantage that the technical applications of yeast in the fermentation industries have stimulated inquiry to so large an extent that we have a considerable accumulation of facts which can be utilized in any such investigation.

When active yeast-cells are suspended in a well aerated nutrient liquid, such as a malt-wort of suitable concentration, and containing an excess of all the organic and mineral substances requisite for their complete nutrition, we should expect a uniform rate of reproduction to be maintained as long as the temperature is invariable and the cells are so sparsely distributed as to avoid mutual interference by crowding ; always provided that no restrictive influence is exerted by the products of growth or fermentation. Under these ideal conditions, if, at stated intervals of time, a census were taken of the number of yeast-cells present in unit volume of the liquid we should expect to find, on plotting the 'density of population' against the time, that the resulting curve was a logarithmic one, and any departure from such an experimental rate of increase would necessarily connote the existence of some factor or factors tending to restrict the free reproduction of the cells. 
When such a suitable nutrient liquid, saturated with atmospheric oxygen, is seeded with a small amount of yeast anywhere in the neighbourhood of 100 c.c. of pressed yeast per $100 \mathrm{cc}$. (an amount equivalent to about I cell per unit volume of $\frac{1}{40}$ б cubic $\mathrm{mm} .{ }^{1}$ ) and cell-counts are made in the haemocytometer at intervals of a few hours, the cell-reproduction expressed as a function of the time always progresses at a much slower rate than is demanded by the exponential law. This is due, as was first pointed out by Adrian Brown, to the reproduction being restricted and limited by the amount of oxygen dissolved in the nutrient liquid.

Quite recently, however, it has been shown by A. Slator (Biochem. Journ., vii (I913), p. 197) that it is possible to realize the logarithmic rate of increase by inoculating the nutrient liquid with very small amounts of yeast, and slowly agitating the containing tubes in a thermostat. The seedings of yeast employed corresponded to from 1,360 to 90,100 cells per c.c., which are equivalent respectively to 0.0003 and 0.0225 cells per unit volume of $\frac{1}{40 \delta \sigma} \mathrm{c} . \mathrm{mm}$.

These are conditions which might be expected to give the theoretical exponential rate- of increase, since, owing to the wide distribution of the cells and the constant stirring, there must have been within the range of the experiments a practically unrestricted supply of oxygen, and consequently an absence of competition for this essential factor of cell-reproduction.

The rate of reproduction of yeast-cells under the ordinary conditions of seeding a nutrient liquid in flasks with limited access of oxygen has been investigated by Adrian Brown (Trans. Laboratory Club, vol. iii (1890); and Journ. Chem. Soc., Trans., 1905, p. I 395).

In two series of experiments in which the nutrient liquid was on the one hand a solution of dextrose with yeast-water, and on the other a maltwort of sp. gr. I.053, flasks containing equal volumes of the solutions were seeded with yeast in amounts varying from 0.145 to 15.75 cells per unit volume of $\frac{1}{4000}$ c.mm., this initial rate of seeding being denoted by $A$. At the end of eighteen hours, the temperature remaining constant, a further count was made in each case; this is denoted by $B$. And the 'rate of cellreproduction'? is given by $\frac{B}{A}$. It was found that 'cell-reproduction proceeds at the maximum rate when the number of cells present is at a minimum, and that the rate falls with a decreasing velocity as the number of cells in the experiments is increased'. Later on the author suggests that

1 One cell per unit volome of $\frac{1}{4000} \mathrm{c} . \mathrm{mm}$. is equivalent to 4 million cells per cubic centimetre. This rate of seeding is closely approximated when o. I gramme of ordinary brewers' yeast (top fermentatiou) which has been washed and pressed between folds of blotting-paper is mixed with 100 c.c. of liquid.

2The 'rate of cell reproduction', $\frac{B}{A}$, really represents the average number of cells derived from a single cell daring the experiment. 
the 'rate of reproduction, $\frac{B}{A}$ is in inverse proportion to the square root of the number of cells of the initial seed-yeast $A$.

If this were strictly correct it follows that the value $\frac{\sqrt{A} \times B}{A}=\frac{B}{\sqrt{ } \bar{A}}$ should be constant for all the experiments in any one series. ${ }^{2}$ On making the calculations it was found that the value for $\frac{B}{\sqrt{A}}$, 'although not constant for each series, nevertheless exhibited a general similarity, which is very remarkable when it is considered that the experiments from which they originate are concerned with the complex functions of living organisms', and 'the relatively close agreement among so many experiments renders it very improbable that such a result has been obtained by mere chance'.

Whilst my own work on this subject fully confirms that of Adrian Brown as regards the limitation of yeast-reproduction by deficient supply of free oxygen, I have found that under similar experimental conditions cell-multiplication stands in a much more simple relation to the time interval than is here stated, and this relation may be expressed as follows :-

During the period of active reproduction of yeast in a suitable medinm in which access of oxygen is limited to that initially present in solution in the liquit, the number of cells present at any moment is directly proportional to the time.

If, for example, we denote the number of cells of the seed-yeast per unit volume by $n$, and the cell-count at any time during active reproduction by $N$, then when either $N$ or $N-n$ is plotted against the time, the result is a straight line, and the 'curve' only begins to depart from the rectilinear direction as the point of maximal cell-reproduction is reached.

This fact is illustrated in the graphs of Fig. I, in which Curve A represents the results of one of my own experiments in which one cell per unit volume $^{2}$ of seed yeast was employed. Curve $\mathrm{B}$ shows the plotted results of a somewhat similar experiment described by Adrian Brown (Trans. Laboratory Club, 1890 ) in which the initial seeding was at the rate of 0.65 cell per unit volume. Both sets of results illustrate the well-marked rectilinear character of the curves during the main period of cell-reproduction, and the comparatively sudden change in their direction as the point of maximal cell-increase is approached. How far these curves depart from the logarithmic rate of increase is shown by the dotted line $C$, which gives the logarithmic curve of cell-increase for Experiment $A$, on the

1 In the original paper (Joum. Chenı. Soc., Trans, $190_{5}^{\circ}$, p. 1398) the above value, owing to a misprint, appears as $\frac{\sqrt{A \times B}}{A}$.

2 The anit volame referred to here and throughout the paper is aरoo c.mm. 
assumption that the successive doublings of the cell-counts had occupied equal intervals of time.

There can be no doubt that the departure from the logarithmic rate in experiments of this kind indicates the existence of some restricting agency which exercises an influence even in the very earliest stages of cell-growth, but it must be one of an excentional and neculiar nature to account for

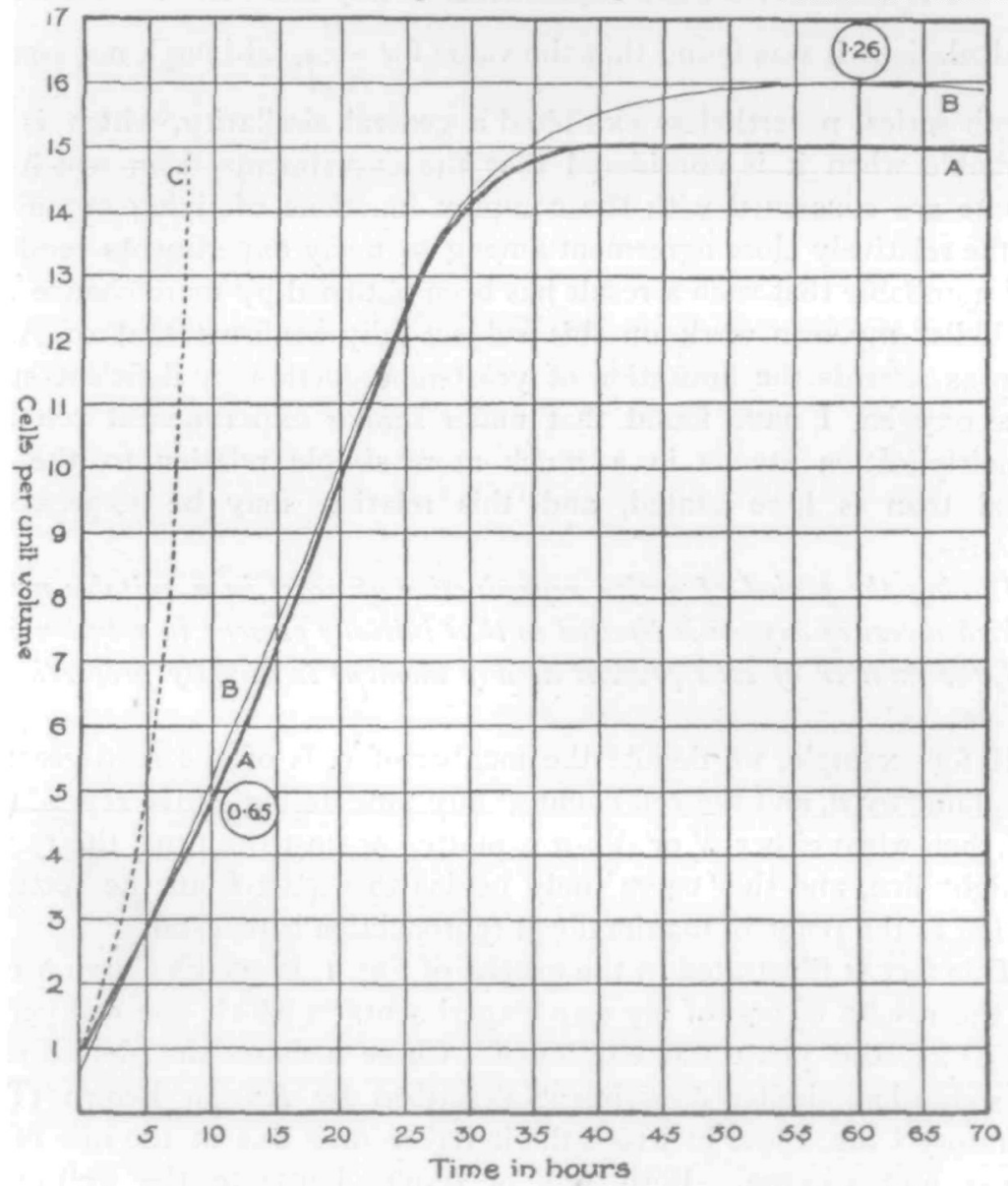

FIG. I. The figures in small circles denote alcohol percentages for Carre B.

the rate of cell-reproduction being so consistently proportional to the time. That mere overcrowding of the cells suffices to account for the result is extremely improbable from the following considerations.

In Experiment A (Fig. I) the seed-yeast amounted to one cell per unit volume of $\frac{1}{4 \sigma 00} \mathrm{c.mm}$., the average diameter of a yeast-cell (assumed to be spherical) being $0.008 \mathrm{~mm}$. If we imagine the unit volume of liquid and its contained yeast-cell to be magnified a little over $1,5^{8} 7$ diameters the unit volume will be represented by a cubic decimetre, and the yeast-cell by 
a sphere of $12: 6 \mathrm{~mm}$. diameter. The apparent volume of the magnified cell will be 1.06 c.c., or about 0.1 per cent. of the total volume of the liquid in which it is suspended. With this distribution the average distance apart of the cells of the yeast-seed would be about eight diameters, and even when the cells have increased to eight cells per unit volume their average distance apart will not be less than four diameters.

When these facts are taken into consideration, and also that the individual cells are bathed in a nutrient liquid of a concentration hundreds of times greater than that requisite to supply all their demands by the process of diffusion, it must be evident that distributions or packings of the cells of such orders of magnitude as we are now considering cannot be responsible for the great slowing down of the cell-increase which is implied by the progression of such increases being an "arithmetical and not a geometrical one. Were this the case there would be some indications of it in the earlier stages by an upward trend of the curve, whereas the more carefully the experiments'are made the more strictly rectilinear is the 'curve' found to be, subject to a slight departure at the commencement, marking a short incubation period before active growth commences.

We are therefore obliged to seek for an explanation of the linear progress of yeast reproduction in some other direction than that suggested by overcrowding and mutual interference of the cells in obtaining their food material from the nutrient liquid containing them.

The two most potent factors in controlling the reproduction of yeastcells are undoubtedly the amount of free oxygen at the disposal of the cell prior to the commencement of reproduction, and the limitation and partial inhibition of growth brought about by the gradually increasing amount of alcohol produced by the fermentative action of the yeast. These facts were thoroughly well established by Adrian Brown (loc. cit.), who also showed that neither the carbon dioxide 7 nor the non-volatile products of fermentation had any appreciable effect. The final conclusions at which he arrived were that in a suitable nutrient liquid yeast reproduction is conditioned and governed mainly by the amount of oxygen originally at the disposal of the cell prior to the commencement. of reproduction, and that it is the exhaustion of the stimulating influence of this oxygen which becomes the limiting factor in arresting the reproductive functions, and not the alcohol produced, since the sharp arrest of cell-growth is often noticed when the percentage of alcohol falls below that necessary to produce any appreciable effect. The finite amount of oxygen initially present in the liquid was also

1 A. Slator (Biochem. Journ., vii (IgI3), p. 201) refers incidentally to the influence of carbon dioxide in retarding yeast-growth. I am unaware of any experiments which show this influence of $\mathrm{CO}$, apart from its effect of preventing access of orygen. Even should it be shown that a distinct retarding effect can be produced by $\mathrm{CO}_{2}$, this would not have any material bearing on the experiments here recorded, since such effect would speedily attain a maximum when the liquid was saturated with $\mathrm{CO}_{2}$, i. e. in the earliest stage of the experiment. 
regarded, and no doubt correctly, as explaining the remarkable fact that under fixed conditions the maximal cell reproduction is independent of the number of cells of seed-yeast per unit volume. A satisfactory explanation was also afforded of the observation that if more cells are added in the form of seed-yeast than correspond to the maximal reproduction then no appreciable cell-increase takes place, the limited amount of oxygen at the disposal of each cell being insufficient to stimulate its reproductive functions.

A few years ago when investigating the assimilation of nitrogen by yeast I had occasion to examine somewhat critically these conclusions of Adrian Brown, and during the course of the inquiry I carried out a considerable number of experiments under varying conditions, especially with a view to determining the quantitative relation of available free oxygen to cell-increase. My results were entirely confirmatory of the proposition that the first limiting factor is the exhaustion of the stimulus given by a relatively very small supply of oxygen, and they further led to an approximation of the absolute amount of oxygen required by a yeast-cell to complete its process of subdivision.

The experiments were for the most part conducted on malt-worts of a sp. gr. varying from $\mathrm{I} \cdot 050$ to $\mathrm{I} \cdot 055$, which contain an excess of all the hutrient materials required for yeast reproduction. Before seeding with a definite amount of yeast the nutrient liquids were fully aerated by strong agitation in the presence of air at the temperature at which the experiment was to be conducted, and immediately after seeding the air in the flasks over the liquid was displaced with $\mathrm{CO}_{2}$. In this manner the free oxygen concerned in the subsequent process was confined to that which was originally present in solution, and the absolute values representing this oxygen were deducible from the known coefficient of solubility of atmospheric oxygen in the liquid. ${ }^{1}$

After seeding the yeast, a series of cell-countings was made in the haemocytometer, thus forming a datum line to which subsequent cell-countings could be referred. A close approximation to any required density of seeding can always be obtained in the first instance by adding definite weights of the freshly grown and washed yeast, after pressing between folds of filter paper. One gramme of an ordinary top-fermentation yeast prepared in this manner and evenly distributed in 100 c.c. of liquid will give a cell-count approximating very closely to to cells per unit volume of $\frac{1}{40 \delta} \mathrm{c} . \mathrm{mm}$.

The actual cultivations were carried on as nearly as possible at a uniform temperature, and successive cell-countings were made at fixed intervals of time. In some cases the progression of cell-reproductions was obtained

\footnotetext{
1 An objection might be raised to this procedure on the ground that immediately on replacing the air in the flask with $\mathrm{CO}_{2}$ the nutrient lignid must begin to lose its free oxygen by a process of diffusion into the oxygen-free atmosphere above it. Practically this objection bas no weight since; as we shall see later, the dissolved oxygen is very rapidly fixed by the seed-yeast when this amounts to anything like one cell per unit volume.
} 
from separate flasks maintained under exactly similar conditions, but in 'most cases the samples for examination were derived from one flask of several litres capacity, so arranged that uniform samples could be forced out by pressure of $\mathrm{CO}_{2}{ }^{1}$

Occasions sometimes arise when it is inconvenient or even impossible to determine the progress of cell-reproduction by direct counting, and we have to fall back on an indirect method which gives equally good results.

As I have fully described this method elsewhere (see Journ. Institute of Brewing, I909, P. 232), I need only refer to it briefly. It is based on the fact that freshly cultivated yeast when seeded in a malt-wort maintains a constancy in both the average dimensions of its constituent cells and in their nitrogen content.

Let us assume that we have determined by the Kjeldahl method the percentage of nitrogen in a san.ple of washed and pressed yeast which we are about to use for seeding a wort, and that we have also determined the number of cells per unit volume of $\frac{1}{4000} \mathrm{~cm}$., which are given by mixing a definite weight of this same yeast with water, and making up the volume to 100 c.c. From these data we can calculate the actual amount of yeastnitrogen in 100 c.c. if the distribution of the cells corresponded to exactly. one cell per unit volume of $\frac{1}{400 \gamma} \mathrm{cm}$. This value I have termed the 'nitrogen coefficient' of the yeast, and since the 'nitrogen coefficient' under the experimental conditions of growth. in malt-wort remains constant, the cellreproduction which occurs between any two intervals of time is a measure of the actual amount of nitrogen assimilated from the liquid; and conversely, if the loss of nitrogen per 100 c.c. has been determined for the same period by two successive nitrogen determinations in the malt-worts filtered from the yeast, this nitrogen loss can be used as a measure of cell-reproduction. As an example, let us suppose that a particular sample of pressed yeast contains in its moist condition 1.98 per cent. of nitrogen, and that $1 \mathrm{grm}$. of this yeast, corresponding to $0.019^{8} \mathrm{grm}$. of nitrogen when mixed with water up to 100 c.c., gives a cell-count in the haemocytometer of ro.39 cells per unit volume. Then the 'nitrogen coefficient' of the yeast (that is to say, the total nitrogen in the 100 c.c. if the distribution of the cells were exactly one cell per unit volume) would be represented by $\frac{0.0198}{10.39}=0.00191$. This value can now be used as a measure of the cell-increase between any two intervals of time, if the loss of nitrogen in the filtered liquid has been determined : we then have

$$
\text { cell-increase per unit volume }=\frac{\text { Loss of nitrogen per Ioo c.c. }}{\text { Nitrogen coefficient of yeast }} .
$$

${ }^{1}$ Certain obvious precautions have to be taken in sach cases to ensure that a sample drawn off in this way is truly representative of the bulk. 
This alternative method of determining the cell-increase gives results which are quite comparable in accuracy with those obtained by direct counting.

Before proceeding to the consideration of the quantitative relations between cell-reproduction and available oxygen, we must discuss the second factor which may, under certain conditions, have an important influence in restricting growth-viz. the alcohol which the yeast produces in the course of an experiment.

Adrian Brown found that additions of alcohol at the commencement had but little effect on the final cell-reproduction if these additions did not exceed about 3 per cent., but that above this amount cell-increase fell off rapidly, although it was not completely inhibited by the addition of 8.4 per cent.

Since the yeast was producing alcohol during its period of increase, the amount of alcohol capable of producing any distinct inhibiting effect must have exceeded 3 per cent.

Instead of merely noting the influence of definite amounts of alcohol on maximal yeast-increase, I have repeated these experiments in such a manner as to be able to follow the whole course of cell-reproduction, taking care that the conditions of oxygenation of the liquid were the same in each case, and that all other conditions were as far as possible identical. The results of these experiments are given in the series of curves of Fig. 2, the amounts of alcohol added at the commencement being respectively 0.5 , $1.0,3.0,4.0,6.0$, and 8.0 grm. per 100 c.c. The figures in small circles at various points of the curves indicate the actual amounts of alcohol present-that is to say; the amount added plus that produced by fermentation. For purposes of comparison there is included the curve of an experiment made under identical conditions but without the previous addition of any alcohol. The general results indicate that when oxygen supply is limited to that afforded by complete aeration of the liquid at the commencement, a sensible effect on the cell-reproduction of the particular class of yeast used ${ }^{1}$ begins to be noticeable when the alcoholic content reaches about 2.5 per cent, and that amounts of about 8.0 per cent. almost entirely inhibit reproduction under these conditions.

If we turn once more to Fig. I, where the alcohol percentages are indicated on Curve B by the figures within small circles, we see that the sudden falling off of cell-reproduction, as indicated by the sharp bend of the curve, cannot have been due to the inhibitory effect of the alcohol produced, since the quantities are too small to have had any such effect. But, although under these special conditions of limited supply of oxygen the gradually increasing alcohol is not a factor in producing, at a certain point, the rapid diminution of cell-reproduction which is so characteristic of all such

\footnotetext{
1 The yeast used was an English high-fermentation yeast.
} 
experiments, it may well become the paramount factor under another set of conditions. If, for instance, a rapid stream of air is urged through the culture liquid, and due regard is paid to keeping up the necessary food supply, then cell-reproduction is essentially controlled and limited by the alcohol factor.

In order to investigate more fully the relation between oxygen supply and cell-increase, a further series of experiments was instituted on an entirely different plan. The general idea underlying these was to cultivate the yeast in a medium containing variable but known amounts of oxygen,

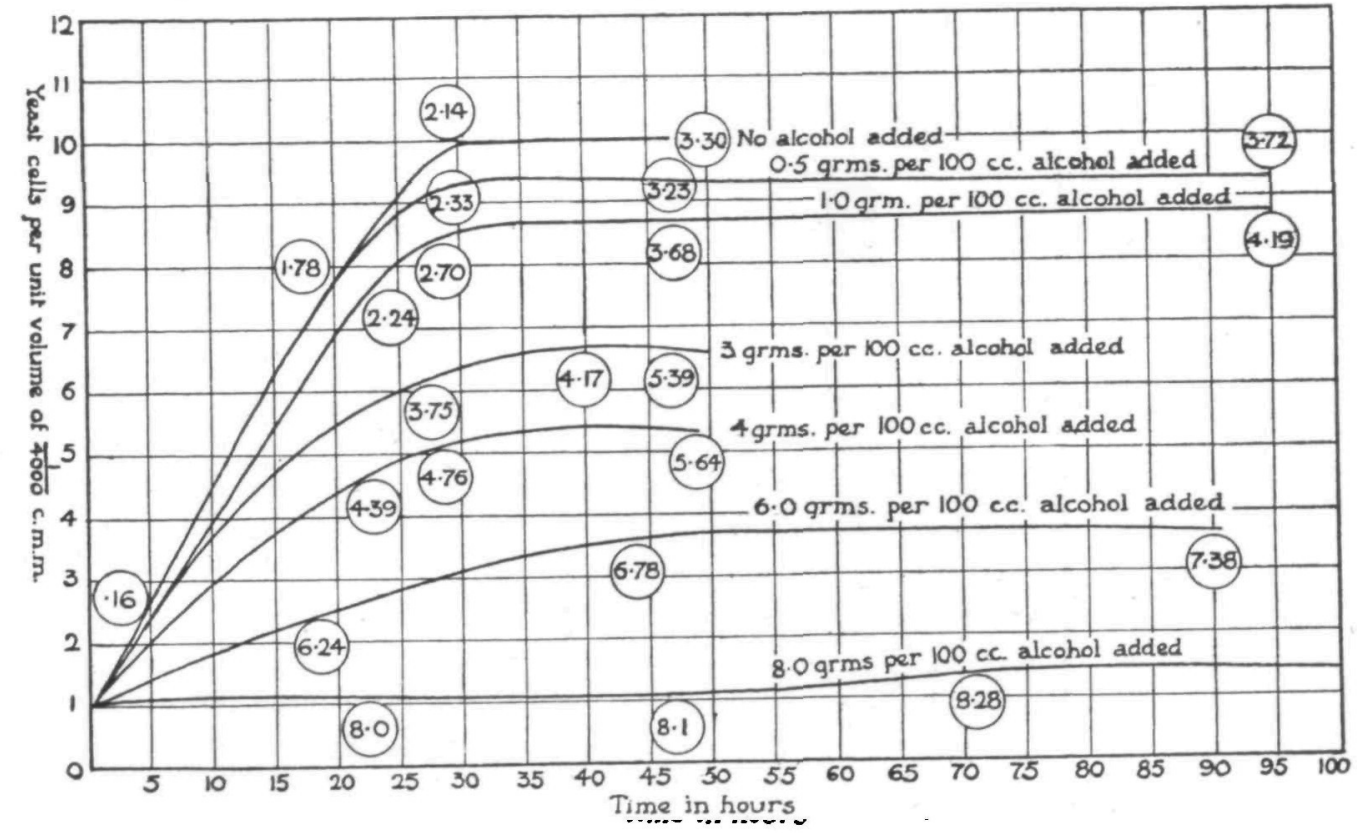

Fio. 2. Yeast cultivations with limited oxygen supply and varying amounts of added alcohol. Temperatures $27^{\circ}-30^{\circ}$ C. Seed-yeast I c.cm. per unit volume ( 0.1 gramme pressed yeast per 100 c.c.) N.B. The figures in small circles denote total percentage of alcohol.

and to express the final reproduction in each case as a function of the available free oxygen.

Malt-wort was again the medium chosen for the cultivations. A flask of about four litres capacity was fitted up as shown in Fig. 3. This was filled to about two-thirds of its capacity with malt-wort, which was then boiled rapidly for an hour or an hour and a half while a constant stream of hydrogen was passed into the flask through tube A, escaping through $C$, the pinchcock B being at first closed. At the close of the boiling process some of the wort was forced into tube B.by closing C. B was then again closed and $\mathrm{C}$ reopened, the flask and its contents being allowed to cool whilst the stream of hydrogen was still passing. This de-oxygenated wort could then be passed over by hydrogen pressure into a series of cultivation 
flasks, one of which is shown at $\mathrm{F} ;^{1}$ these were of about 225 c.c. capacity; and were fitted in such a manner that the gas-delivery tube did not extend below the rubber stopper, in order that at the final operation the flasks could be completely filled with the wort, which was also driven round the bend $\mathrm{E}$.

Some of the de-aerated wort was then withdrawn from the large flask, and was fully saturated with air by strong agitation, the temperature being noted. A measured quantity of this fully aerated wort, along with a weighed

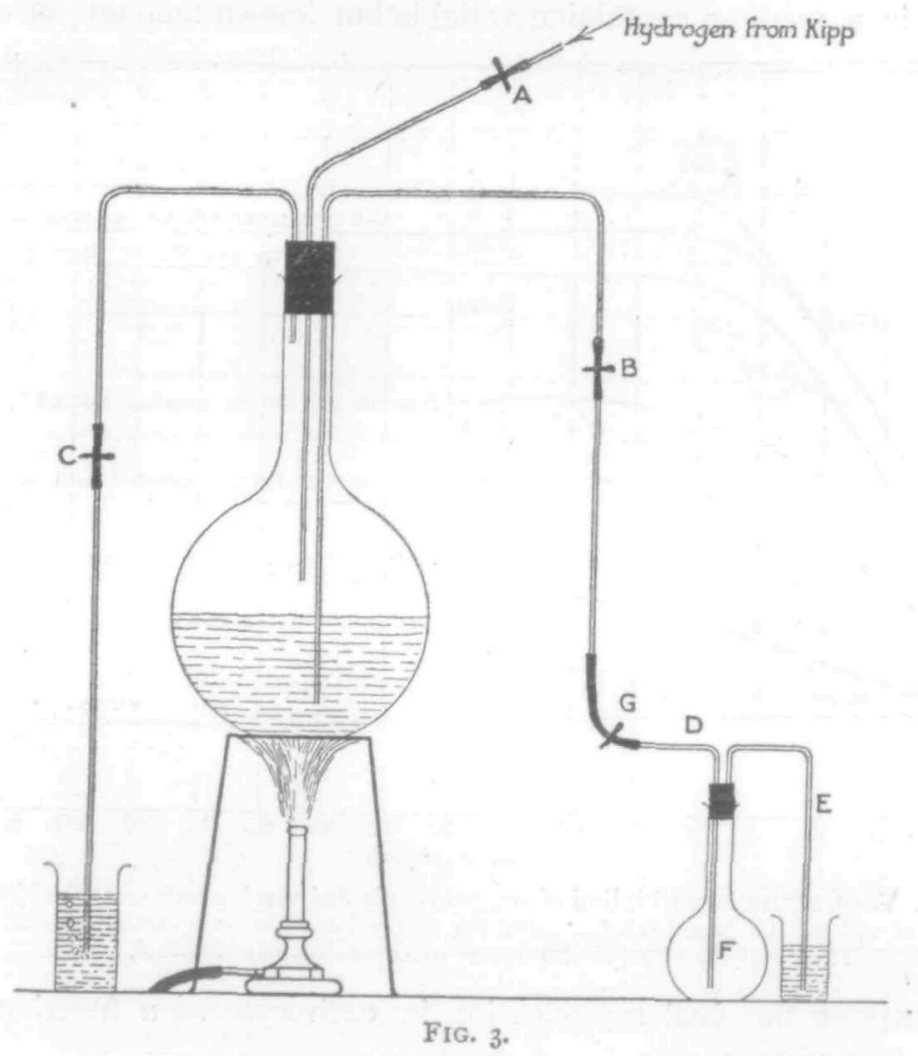

amount of freshly cultivated and pressed yeast, generally amounting to 0.2 grm., was transferred to one of the small flasks $F$, which was then rapidly and completely filled up with de-aerated wort through the tube $D$. The pinchcock $\mathrm{G}$ was then closed and the rubber connexion severed just behind it.

In this manner a series of flasks was obtained containing known proportions of fully aerated and de-aerated wort with definite amounts of yeast. A complete series consisted of nine such flasks ranging from fully aerated

1 Before inserting the plag of $F$ the supply tube B, G, D must be completely filled with the de: perated wort. 
to completely de-aerated wort, the intermediate members of the series being mixtures of the two in known proportions.

In filling the flask with completely de-aerated liquid special precautions had to be taken in introducing the seed-yeast. This was spread on a thin cover-slip and dropped into the empty flask, a current of hydrogen being then passed through the flask for some time before it was filled with the oxygen-free wort.

All the flasks were then allowed to ferment slowly at the same temperature for ten days or so with their outlet tubes dipping under mercury.

Since the flasks were quite full it is manifest that as fermentątion pro-

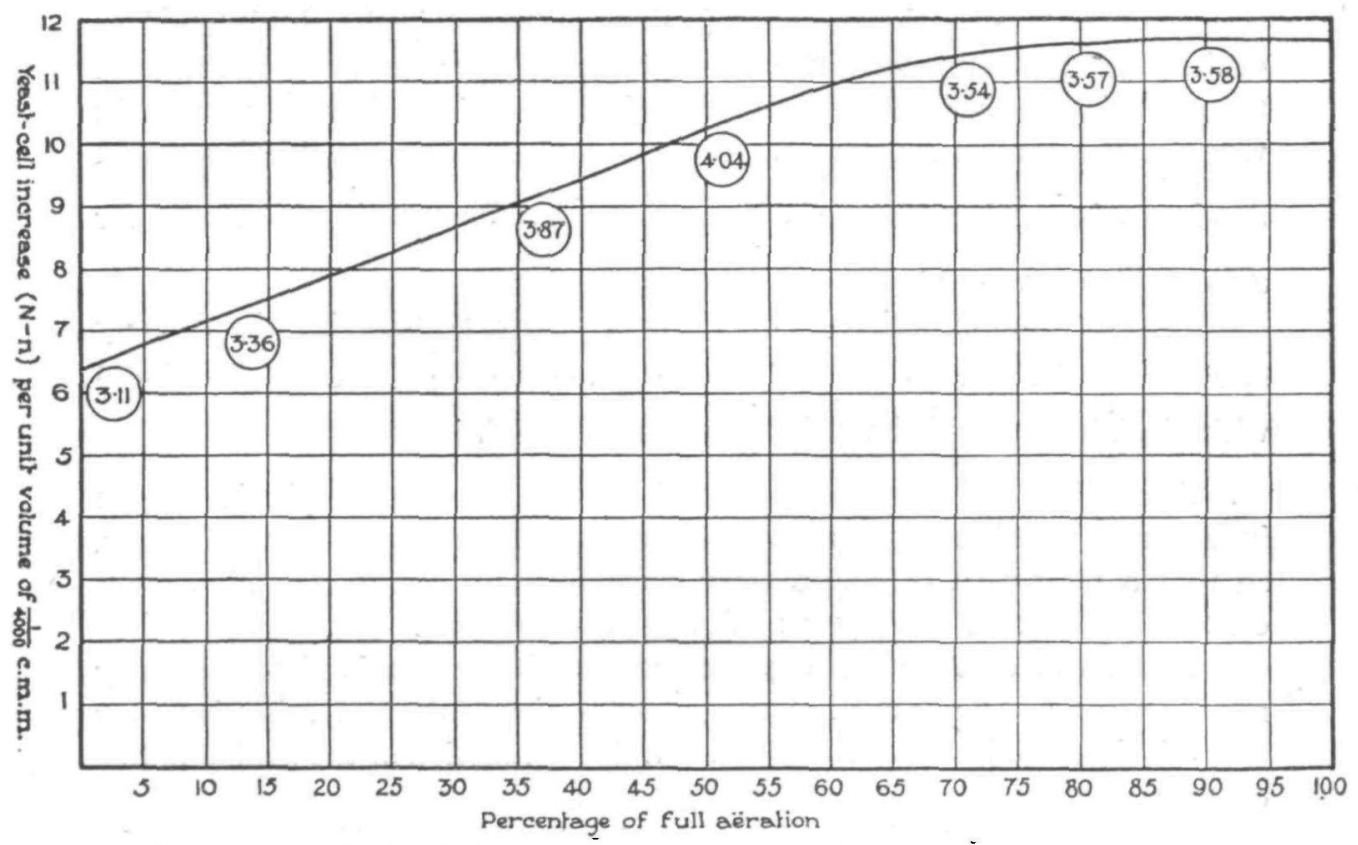

Fic. 4. Curve showing influence on yeast-cell reproduction of varying amounts of dissolved oxygen in the culture-liquid (malt-wort). The cultures were made with definite mixtures of fally aerated worts and of wort fally deprived of oxygen. Seed-yeast - I cell per unit volame. The figures in small circles denote percentages of alcohol found at the termination of eacb experiment.

ceeded there would be a slight loss of liquid from the outlet tubes and the upper part of the flasks in the first stages of fermentation. It was therefore more convenient to determine the cell-reproduction by the indirect method of nitrogen loss than by cell-counting. The nitrogen coefficient of the seedyeast was-therefore ascertained, and also the number of cells per unit volume given by mixing a definite weight of it with water and making up to 100 c.c. The estimation of the nitrogen in the wort before and after fermentation then completed all the necessary data.

Fig. 4 shows the result of plotting the maximal cell-increases attained 
in nine such experiments with the same wort and the same seed-yeast, the conditions of cultivation in all cases being maintained constant with the exception of the degree of aeration, which is the only variable. The cellincreases per unit volume are indicated on the line of ordinates, whilst the intervals on the abscissa line show the percentages of 'fully aerated wort contained in the mixture.

It will be noted that up to 65 or 70 per cent. of complete aeration the cell-increase is directly proportional to the available oxygen present in the culture medium at the commencement of growth, and that beyond this point further increments of oxygen produce a smaller and ultimately vanishing effect.

In order to carry the argument further and to obtain the absolute values of the free oxygen involved in these experiments, we must know the ratio of the coefficient of solubility of atmospheric oxygen in malt-wort to that in water at the same temperature. If we denote the former value by $c_{1}$ and the latter by $c$, then the ratio $\frac{c_{1}}{c}$ as given by Pasteur is about 0.86 for a wort of sp. gr. I.060.

In a series of experiments on worts of sp. gr. 1.050, using the Adeney apparatus for pumping out the dissolved gases after complete saturation with air, I have found the ratio $\frac{c_{1}}{c}=0.82$ at $16^{\circ} \mathrm{C}$.

According to Roscoe and Lunt, the solubility of atmospheric oxygen in water at $16^{\circ} \mathrm{C}$. and $760 \mathrm{~mm}$. pressure is 0.682 c.c. per 100 c.c. of water, so that a malt-wort of sp. gr. I.050 when fully saturated with air should contain $0.682 \times 0.82=0.559$ c.c. of oxygen per 100 c.c.

From the curve of Fig. 4 we see that its course is almost exactly rectilinear up to 60 per cent. of oxygen saturation of the wort, that is to say that within these limits cell-increase is a linear function of the available free oxygen:

This 60 per cent. of complete saturation is represented in absolute units by $0.60 \times 0.559=0.335$ c.c. of oxygen per I00 c.c. The consumption of this amount of oxygen has resulted in the production of $11 \cdot 0-6 \cdot 4=4 \cdot 6$ cells per unit volume of $\frac{1}{40 \%} \mathrm{c} . \mathrm{mm}$., so that for the production of one cell per unit volume there has been used up per 100 c.c. an amount of oxygen represented by $\frac{0.335}{4.6}=0.07$ c.c. But one cell per unit volume of $\frac{1}{400}$ c.mm. is equivalent to 400 millions of cells per 100 c.c., so that each single cell of this aggregate has on an average required for its production the expenditure of $\frac{7 \times 10^{-8}}{4 \times 10^{8}}=1.7 \times 10^{-10}$ c.c. of oxygen.

Now the average volume of a yeast-cell, assuming it to be a sphere of $8 \mu$ in diameter, is $2.68 \times 10^{-10}$ c.c., so that the above-mentioned 
volume of oxygen requisite for the subdivision of one yeast-cell into two, when expressed as a fraction of the volume of the original cell, is $1 \cdot 7 \times 10^{-10}$ $\div 2.68 \times 10^{-10}=c .63$.

It will be noted from the curve of Fig. 4 that even after complete de-oxygenation of the culture medium there has been a cell-increase equivalent to about 6.5 cells from each single cell of the seed yeast. It might be supposed that this is due to a small amount of oxygen left in the liquid, or to its subsequent introduction by faulty manipulation. It is impossible, however, to accept this explanation, since similar results are obtained when extreme care is taken to eliminate these sources of error. It is no doubt a fact that the yeast-cell has a limited power of reproduction under strictly anaerobic conditions, owing, as we shall see later, to its power of storing up oxygen prior to the seeding process.

We may now turn to the effects which variations in the amount of seed-yeast exert on cell-reproduction when all other conditions remain the same.

Adrian Brown came to the conclusion that when the supply of free oxygen is constant, the cells increase up to a certain maximal amount per unit volume which remains constant even when the amount of seed-yeast varies considerably.

With certain limitations this conclusion is no doubt approximately correct, especially when we compare the true values of the cell-increases $N-n$ instead of the final counts $N$, and care is taken that the available oxygen is strictly identical in the various experiments. In my own experiments this was ensured by arranging, in the manner already described, that the available free oxygen was confined to that dissolved in the culture-liquid, and that no further access of oxygen was possible at any subsequent stage.

Under these conditions, and provided the seed-yeast does not fall below one cell per unit volume, not only is the maximal reproduction $N-n$ constant, or nearly so, for considerable variations in the seeding, but during the reproductive stage the number of new cells formed in a given interval of time is also constant and independent of the rate of seeding.

This is shown in Figs. 5 and 6 . In Fig. 5 the results are given of three of my own experiments in which the seed-yeast amounted to $0.93,1.87$, and 2.8 cells per unit volume.

Fig. 6 gives the curves which I have deduced from a series of Adrian Brown's experiments, in which the cells of seed-yeast per unit volume initially amounted to $\mathrm{I} \cdot 57,2 \cdot 35$, and $3 . \mathrm{I} 4$ respectively.

The general parallelism of these curves bears out what has been said as to the progressive and final reproduction being independent of the original seeding. They are phenomena which might have been deduced from the fundamental fact that there is, within certain limits, a quantitative relation between cell-multiplication and the supply of free oxygen. 
I have stated that the above' relations do not hold good' when the amount of seed-yeast falls much below I cell per unit volume. If the initial seeding is as low as 0.1 cell per unit volume, the departure from the above rule is very great. The explanation of this is to be found in the behaviour of the seed-yeast to the dissolved oxygen at the commencernent. As we shall see a little later, the first action of the yeast, long before there are signs

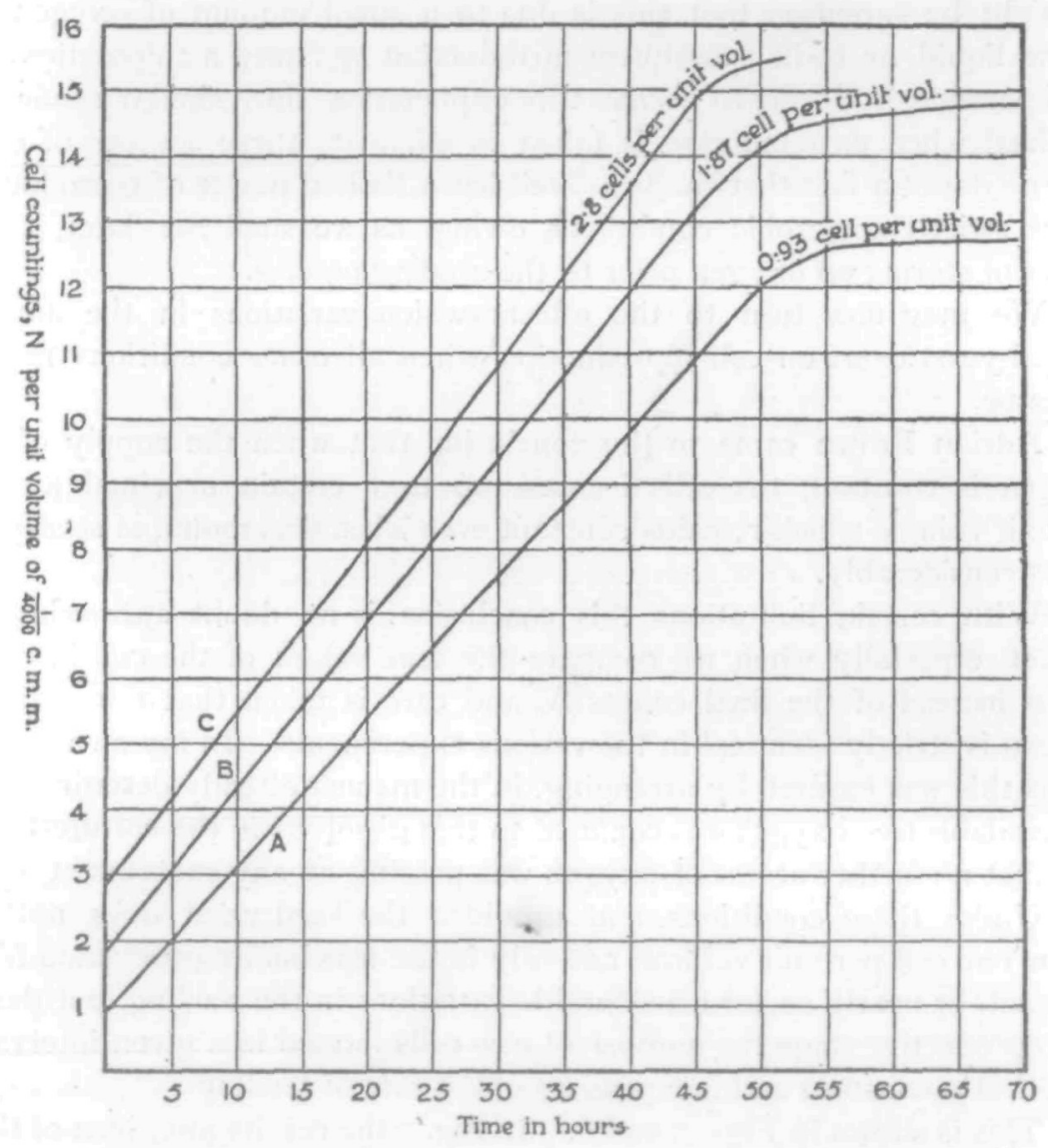

FiG. 5. Fermentations with limited supply of oxygen, and with varying initial amounts of seedyeast, $17.0^{\circ} \mathrm{C}$. A. Seed-yeast 0.93 cell per unit volume. B. 1.87 cells per unit volume. C. 2.8 cells per tunit volume.

of reproduction, is to absorb and fix the dissolved oxygen. This absorption is very' rapid with a 'density of population' of yeast-cells equivalent to I cell or more per unit volume, but with anything less than this the rate of , absorption falls off rapidly, and with anything like 0.1 cell per unit volume the absorption is so slow that sufficient time elapses to allow a more or less complete diffusion of the dissolved oxygen into the inert gas which replaces the air above the liquid. Under these conditions reproduction is relatively 
slowed down and is no longer comparable with that observed for higher rates of seeding.

Pasteur, in his 'Études sur la bière', describes certain experiments which he made to determine the rate at which free oxygen dissolved in malt-worts is absorbed by yeast, making use of the Schiitzenberger method for oxygen estimation. He gives the particulars of an experiment made in a brewery in which the free oxygen dissolved in a malt-wort was determined hour by hour after the addition of the yeast, the temperature being $6^{\circ} \mathrm{C}$.

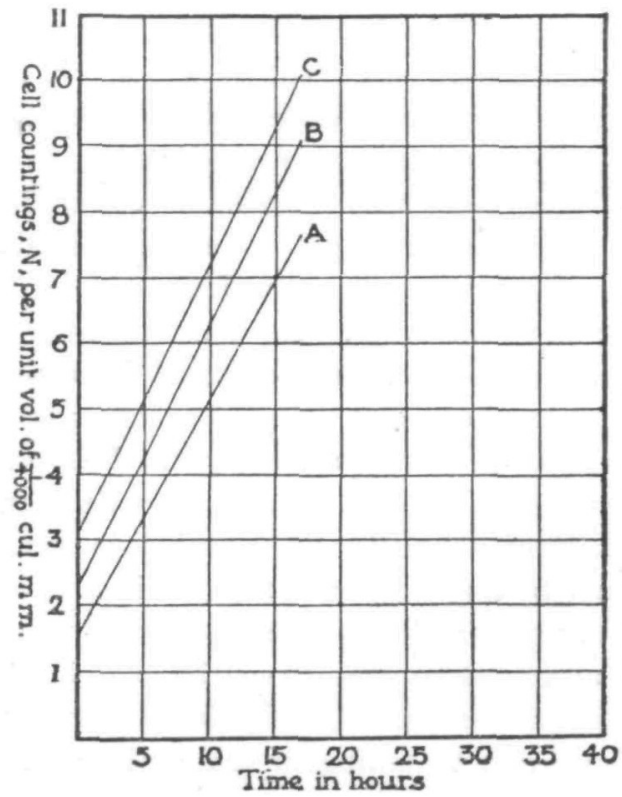

Fia. 6. Plottings of three experiments of Adrian Brown (see Journ. Chem. Soc., 1905, p. I 398 ) showing final countings of yeast-cells after cultivation for seventeen hours, the initial seed-yeast being varied in amount. Curve A. Seed-yeast 1.57 cells per anit volume. Curve B. Seed-yeast 2.35 cells per unit volame. Curve C. Seed-yeast 3.14 cells per unit volume.

From the particulars given of the amount of yeast used, it must have been equivalent to about $\mathrm{I}$ cell per unit volume of $\frac{1}{400 \mathrm{c}} \mathrm{c.mm}$. The results which were plotted out show that within six hours the residual oxygenation had only about 25 per cent. of the initial value, and that at the end of twelve hours from the commencement all the dissolved oxygen had disappeared. With double the amount of yeast the free oxygen disappeared in less than half the time. Pasteur further states that when this free oxygen had been removed from the wort the yeast-cells still showed no signs of reproduction, 1 but they had assumed a younger and fuller appearance, and he draws the

1 It must be remembered that the yeast nged in this experiment of Ptstear was a 'bottom yeast' which was functioning at a low temperature; hence oxygen absorption and initial rate of reprodaction were relatively slow. 
conclusion that the oxygen had been stored up in them, and functioned as a primum movens of their subsequent life and nutrition. If for 'life and nutrition ' we read 'power of reproduction', this is a striking instance of the prophetic insight of genius, for we have seen that this primum movens is not only the essential determinant of cell-reproduction, but that the stored-up oxygen exerts a 'potential' which is quantitatively related to the amount of subsequent reproduction.

The limited growth which, as we have seen, yeast exhibits when seeded in a liquid from which oxygen has been wholly excluded (see p. 209), so far from being in opposition to this view is really in its favour, for owing to the very nature of the experiments the cells of the seed-yeast in such a case must have carried with them an 'oxygen charge' which enabled them to reproduce to a certain limited extent even under anaerobic conditions. ${ }^{1}$

I have further investigated this remarkable power of yeast to store up oxygen for further use by submitting it to long-continued aeration before it was used for seeding, and in some cases I have passed oxygen through a suspension of the yeast in water. Such treatment in all cases failed to give a yeast which, after separation, possessed increased potentialities of growth, and in some cases the power of reproduction was actually diminished, especially when it was treated with pure oxygen. It seems to be impossible to give a yeast a higher effective charge of oxygen than it has ordinarily acquired by processes of washing and filtration in contact with air, and apparently one cannot by any further treatment in this direction make up for the lack of free oxygen in the culture medium, since on this factor and on the subsequent access of oxygen from the outside mainly depends the final degree of reproduction up to the point at which inhibitory causes come in, such as those due to failing of essential nutrients, and formation of alcohol.

At ordinary temperatures yeast suspended in its nutrient liquid is a very complete and rapid absorber of dissolved oxygen, much more so in fact than might be imagined from the experiments of Pasteur just alluded to, which were made at a temperature of $6^{\circ} \mathrm{C}$. I have studied the actual rate of absorption by varying proportions of yeast-cells by suspending these in water fully saturated with atmospheric oxygen, and noting at intervals the gradual disappearance of the oxygen.

The so-called Winkler process for determining the dissolved oxygen is

1 There is one fact which seems to be agrinst the idea that this anaerobic reproduction was doe to the 'oxygen charge' of the seed-yeast. If this were so one would expect that on varying the amount of seed-yeast the maximal number of cells produced anaerobically would be proportional to the seed-yeast employed, whereas it was fond that the maximal cell-reproduction $N-n$ was constant and independent of the initial seeding. This is the resalt which might be expected if there was any residual oxygen in the colture-liquid, bot the conditions of the experiments negative this explanation. Another possible explanation of this fact may be that during fermentation under . strictly anaerobic conditions a small amount of peroxide of hydrogen may be produced, and that the ferrous salts in the natrient liquid may be the 'carrier' of the oxygen of the peroxide to the yeast. 
well adapted for this purpose, since the presence of the yeast-cells does not sensibly affect its accuracy. A description of the method has been given by Clowes and Biggs (Journ. Soc. Chem. Ind., April I5, 1904).

A stoppered bottle of from 300 to 400 c.c. capacity is filled with the water to be examined, due precautions being taken to avoid agitation during the process. About $I$ c.c. of a strong solution of manganous chloride is then added, followed by 2 c.c. of a solution containing 33 per cent. of alkaline hydroxide and Io per cent. of potassium iodide. The bottle, which must be quite full, is then closed with its stopper, taking care to avoid the inclusion of any air bubbles, and is inverted several times in order to mix the liquid thoroughly. The manganous oxide which is precipitated rapidly absorbs any free oxygen which is present, and in order to complete the reaction the bottle is put in the dark for fifteen minutes. Its contents are then acidified with from 2 to 3 c.c. of strong hydrochloric or sulphuric acid, which dissolves the precipitate, leaving the liquid slightly coloured with iodine. This liberated iodine is a measure of the original amount of free oxygen present in the water, and is titrated with a standard solution of thiosulphate, of which the oxygen value is known, using starch as the indicator.

If the experiment is repeated with another sample of the water which has been fully aerated at the same temperature, then the ratio of the amount of thiosulphate solution employed in the two experiments gives the degree of oxygen-saturation of the first sample when full saturation is represented as unity.

The curves in Fig. 7 show the rates of absorption of dissolved oxygen from fully aerated water at $15^{\circ} \mathrm{C}$. by amounts of yeast corresponding to $\mathrm{I} \cdot 0,2.0$, and 3.0 cells per unit volume respectively, the actual amounts of pressed yeast per 100 c.c. being $0.1,0.2$, and $0.3 \mathrm{grm}$.

It will be noted that above I cell per unit volume the absorption of oxygen is approximately proportional to the number of cells per unit volume, and that with the small amount of only $0.3 \mathrm{grm}$. of pressed yeast per 100 c.c. or 3.0 cells per unit volume, the absorption is complete in two and a half hours.

It might reasonably be expected that a reaction of this kind would show a tendency to slow down as the concentration of the dissolved oxygen gradually decreased. Absorption of dissolved oxygen by the yeast-cell progresses, however, as a linear function of the time, just as the invertive, fermentative, and reproductive actions do. There is no doubt a common cause controlling all these functions, which is to be found in the fact that they are all dependent on cell metabolism, and that the processes involved, although in some cases rapid as judged by ordinary standards of time, are very slow compared with the relatively rapid processes of diffusion by which the materials involved get access to the ccll-protoplasm from the surrounding 
medium. In such cases diffusion can only become the limiting factor at very low outside concentrations, as shown by Slator for the fermentative faculty, and where diffusion ceases to limit the reaction there must always be a tendency to linear rather than logarithmic rate of change.

If the water from which suspended yeast has absorbed all the dissolved oxygen. is again saturated with air by strong agitation, the cells recommence their absorption at almost the same rate, and it is only by repeating such an experiment several times, or by passing strong currents of air through the

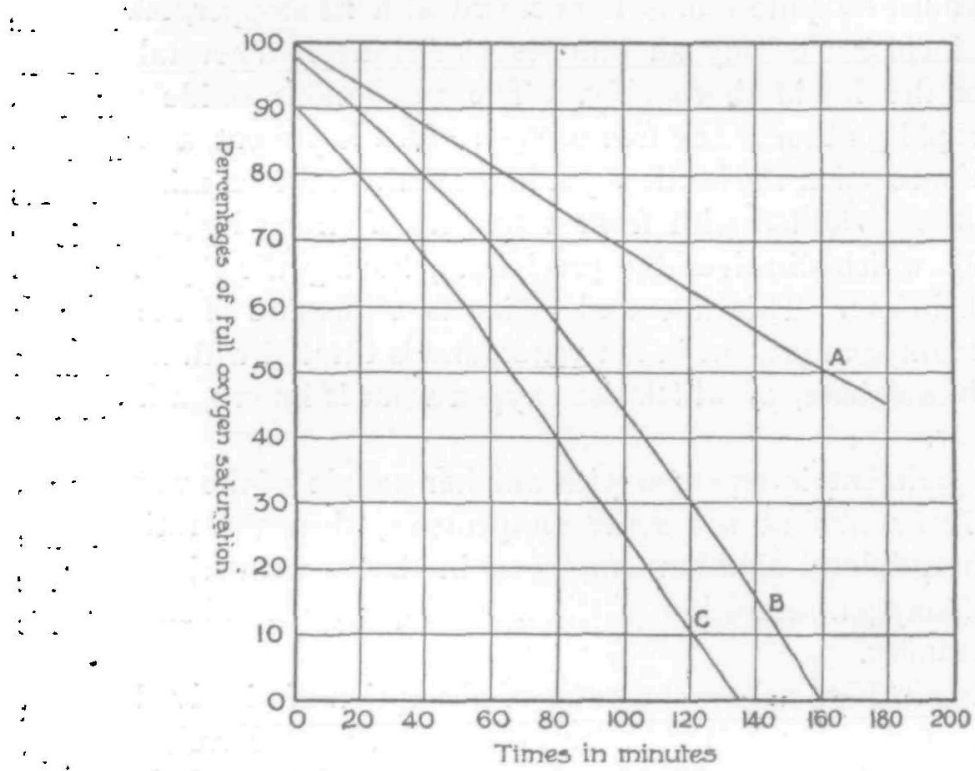

FiG. 7. Carve ghowing the rectilinear rate of absorption of dissolved oxygen by yeast at $\mathrm{I} 5^{\circ} \mathrm{C}$. Llquid used was water saturated with atmospheric air. The values on the line of ordinates give the percentages of foll saturation remaining, and measare the absorption of orygen. Seed-yeast ased : A. 0.1 grm. pressed yeast per 100 c.c. $=1$ cell per unit volume. B. 0.2 grm. pressed yeast per 100 c.c. $=2$ cells per unit volume. c. 0.3 grm. pressed yeast per 100 c.c. -3 cells per unit volame.

liquid for an hour or two, that any marked diminution in the absorbing power is noticeable.

The main facts which have been established experimentally, with regard to the reproduction of yeast-cells in a nutrient liquid containing dissolved oxygen, and an excess of all the mineral and organic substances requisite for their full nutrition, may be summarized as follows :

I. When the available oxygen is limited to that initially contained in the liquid, the number of yeast-cells per unit volume tends to attain a maximum which is independent, or nearly so, of the number of cells of seed-yeast per unit volume, but is conditioned in the first instance by the initial amount of this dissolved oxygen. 
2. Within certain limits of oxygen supply, the maximal reproduction is strictly proportional to the initial amount of this oxygen.

3. The rate of reproduction under these conditions is not logarithmic, but is a linear function of the time.

4. The dissolved oxygen does not remain as such in the liquid during the reproductive period, but is rapidly absorbed by the seed-yeast before . cell-budding commences.

A due consideration of the important fact mentioned in (4), and of everything which it implies, enables us to give a satisfactory explanation of all the phenomena we are dealing with.

Although the main controlling influence on cell-reproduction is due to the free oxygen originally present in the nutrient liquid, this oxygen is absorbed very rapidly by the seed-yeast, the subsequent reproduction of which is brought about under conditions which, as regards the liquid itself, are anaerobic. We must therefore regard the potentiality of reproduction as being impressed on the cell at the very outset by the oxygen which it has absorbed, and that a quantitative relation exists between this absorbed oxygen and the number of subdivisions which the initial yeast-cells can finally make. The action is, in fact, one of induction, and all the known facts can be explained if we assume the equal partition of the available oxygen between the initial cells, and the consequent variability of the oxygen charge which these cells must receive when the ratio of the seed-yeast to the available oxygen varies.

In order to illustrate this point, let us consider three hypothetical cases, $A, B$, and $C$, in which we have a nutrient liquid such as a malt-wort, saturated with atmospheric air, and therefore containing about 0.5 c.c. of dissolved oxygen per 100 c.c. We will assume that $A$ is seeded with I cell of yeast per unit volume, B with 2 cells, and $C$ with 4 cells, ${ }^{1}$ and that further access of oxygen is prevented during the reproductive period. Under such conditions we should expect to find, at the termination of the reproductive period, about 16 cells per unit volume in each case, the final cellcount being independent, or nearly so, of the rate of seeding. This result can be explained as follows: In all three cases the dissolved oxygen is absorbed within a short time by the seed-yeast, but it is manifest that, when this has taken place, the initial oxygen charges of the individual cells in $A, B$, and $C$ respectively must vary inversely as the original cell-countings, and will therefore be represented by the ratios $I: \frac{1}{2}: \frac{1}{4}$.

Since, within the limits of our experiment, the maximal cell reproduction is known to be proportional to the oxygen supply, the number of possible cell-divisions of any individual cell in $B$ will only be one-half of that in $A$, but since the initial number of cells in $B$ is double that of $A$, the final

\footnotetext{
1 These seedings approximately represent volames of yeast-cells equivalent to $0.1,0.2$, and 0.4 c.c. per 100 c.c. of liquid.
} 
limit of reproduction, as determined by cell-counting in a unit volume of liquid, should be the same in both cases. Again, the reduced number of subdivisions in $\mathrm{C}$, due to the reduction of the oxygen charge on the individual cells to one quarter, is compensated by the fourfold number of seed-cells in this case.

This fundamental idea of the dependence of reproduction on the intensity of the initial oxygen charge also gives a complete explanation of the rate of reproduction being linear instead of logarithmic, for at each cell-subdivision the oxygen charge of the mother-cell must be halved, consequently the time required for the next subdivision of the mother-and daughter-cell will be double that required for the previous subdivision.

These considerations, taken in conjunction with the experimental data given in this paper, afford a quantitative proof of the correctness of the idea, first expressed by Pasteur, that the oxygen originally absorbed by the yeast from its surrounding medium is the primum movens which determines its subsequent power of reproduction.

The question now arises as to the limits of reproductive power which are imposed on the cell by this initial absorption of oxygen.

Although a yeast-cell can, under favourable conditions, continue to take in oxygen from the surrounding liquid if this is maintained saturated with air, the cell can only store up a limited amount of oxygen in a form available for subsequent reproduction. All attempts to increase this effective 'oxygen charge' by previously submitting the seed-yeast to strong aeration, or even by passing pure oxygen through the liquid, were unsuccessful. The yeast under these circumstances continues to take in oxygen, but its potentiality of reproduction is not thereby increased. Whether the whole of the surplus oxygen absorbed, over and above that required for the reproductive 'charge', is used up in ordinary processes of respiration appears to be very doubtful, and much more work requires to be done before this question can be definitely answered.

Meanwhile, the experiments which have been summarized in the curves of Fig. 4 give us some information about the actual values of an oxygen charge requisite to produce a given amount of cell-reproduction. In these experiments, in which the nutrient liquids contained known and graduated amounts of dissolved oxygen and were initially seeded at a uniform rate of one cell per unit volume, it is seen that a direct proportionality exists between oxygen supply and maximal cell-reproduction, up to a point within about 60 to 65 per cent. of complete saturation of the liquid with atmospheric oxygen. This point corresponds to an initial oxygen content of the liquid of about $0.6 \times 0.559=0.335$ c.c. of oxygen per 100 c.c. of the liquid.

When the oxygen in the liquid is increased beyond this point up to full saturation with air, although further yeast reproduction takes place, the final cell-increase is no longer strictly proportional to the available oxygen 
initially present, and from the course of the curve we may conclude that, with a liquid seeded with yeast at the rate of one cell per unit volume, the stimulation to reproduction ceases when the initial oxygen supply is equivalent to about 0.5 c.c. per 100 c.c. of the liquid.

Since one cell of yeast per unit volume is equivalent to about 0.1 c.c. of yeast per 100 c.c. and the whole of the oxygen is rapidly taken up from the liquid, it is evident that under the above conditions the volume of oxygen taken up by each cell and constituting the 'oxygen charge' is about five times the volume of the cell itself.

\section{PART II.}

\section{The Metabolism of the Yeast-cell, with Spectat Reference to the Thermal Phenomena of Fermentation.}

The earlier ideas that the yeast-cell, by its mere presence, is able to exert an extraneous transforming influence on certain substances dissolved in the surrounding. medium have now proved to be erroneous. All known facts point consistently to these changes taking place exclusively within the cell, and they therefore connote a constant centripetal flux of material through the cell-wall, and a counter flux of the metabolites of equal or nearly equal amount in the opposite direction.

We can obtain some idea of the extraordinary activity of this metabolic ' mill' by determining the ratio of the mass of the cell to that of the sugar fermented in a given time, or we can, if we prefer it, indicate the activity under given conditions by stating the time necessary for the cell to transform its own weight of sugar into alcohol and carbon dioxide.

Another way of illustrating the activity of the cell is to study the thermal phenomena of fermentation, and to refer the liberation of energy to the cell in such a manner as to show to what extent the temperature of the cell would be raised in a given time if the liberated heat were all concentrated on the cell, and had not to be shared by its environment.

The advantage of this second method is that it gives us a rough means of comparing the metabolic activity of a yeast-cell with that of a warmblooded animal ; but it takes for granted that we know the amount of heat energy evolved during the breaking down of a unit weight of sugar by the cell, a value which is still to some extent in dispute.

The earliest attempts to ascertain the actual amount of heat evolved during the splitting up of sugar into alcohol and carbon dioxide were made by Berthelot and by C. V. Rechenberg, whose methods, however, were entirely indirect, since they were based on a determination of the differences between the calculated heat of formation of dextrose and the calculated heat of formation of the equivalent amounts of alcohol and carbon dioxide. 
Berthelot's final result, after making a small correction for the non-volatile products of fermentation, indicated that the gramme molecule of dextrose liberated on fermentation 32.07 kilogram-centigrade heat units, corresponding to $178 \cdot 1$ calories per gramme of sugar.

But the possible errors of such indirect methods are very great, and are all accumulated on the final result.

In I 895 Bouffard (Compt. rend., I 895, I 21, 357) made the first attempt to determine the heat of fermentation by direct means, employing for this purpose a Berthelot's calorimeter containing a litre of grape-juice, to which had been added a further quantity of dextrose. When all due corrections were applied, Bouffard's experiments pointed to the heat of fermentation of dextrose being $K 23.5$, or I 30 calories per gramme of dextrose.

A few years later, the problem was attacked by Adrian Brown (Journ. Fed. Inst. Brewing, vol. vii, 190r, p. 93).

The great difficulty which had been experienced by Bouffard was one which is incidental to all measurements of thermal effects produced by comparatively slow reactions, viz. that of determining the rate of cooling of the calorimeter and its contents. Adrian Brown reduced this possible error by employing as his calorimeter a fermenting vessel of about 1,300 .gallons capacity, as used in a brewery under the 'high fermentation' system.

The liquid operated upon in this vessel was an ordinary brewer's wort, and observations were made at sufficiently short intervals almost to eliminate the cooling correction.

The amount of sugar (maltose) fermented between any two intervals corresponding to a definite rise of temperature was ascertained from the loss in specific gravity of the liquid after deprivation of its alcohol, and the application of the known 'divisor' for maltose. The specific heat of the wort being taken at 0.9678 , the final conclusion was arrived at that the heat liberated by the fermentation of I $\mathrm{grm}$. of maltose is I I $9 \cdot 2$ calories.

Within the last few years I have made various attempts to determine the heat of fermentation of maltose by a method substantially the same as that used by Adrian Brown. The principal points of difference were that I used larger vessels, varying in content from 1,800 to 14,000 gallons, and that the fermented sugar was estimated from the amount of alcohol formed, the exact ratio of alcohol to sugar at different stages of the fermentation of a malt-wort having been previously determined in the course of a separate investigation. ${ }^{1}$

Twelve such experiments were made, and a critical examination of the results points to a value of about 125 calories as representing the heat of fermentation of $\mathrm{I} \mathrm{grm}$. of maltose, this value including the heat due to hydrolysis of the maltose at the moment of its fermentation. Brewing.

1 See Reports on Original Gravities in process of pablication in the Journ. of Fed. Institutes of 
The immediate experimental data on which this result was founded consist of a determination of the actual amount of sugar fermented within short intervals of time corresponding to a rise of temperature of the liquid of from one to two degrees centigrade.

In order to refer the rise of temperature to a definite weight or number of yeast-cells in a given volume of the liquid, a series of cell-countings were made at the beginning and end of each time-interval, by means of the haemocytometer. If the observations were made at a time when cellreproduction had ceased, the initial and final countings were, of course, practically identical, but in those cases in which the 'oxygen charge' had still not spent itself and the yeast was still reproducing, the arithmetical mean of the initial and final countings was taken as representing the average number of cells actively engaged in fermentation within the period.

The actual amount of maltose which had disappeared during each period of observation was determined from accurate estimations of the alcohol produced, and from these data were obtained the weights of maltose which had disappeared from Ioo c.c. of the liquid in one hour, under the influence of a definite number of yeast-cells per unit volume of the liquid.

For convenience in further calculations and comparisons, this last value was further reduced so as to represent the weight of maltose per Ioo c.c., which in one hour would have been fermented by a definite unit weight of yeast, or by a definite distribution of so many cells per unit volume, on the assumption (capable of proof) that under fixed conditions the amount of sugar fermented is proportional to the yeast present.

A convenient standard to take for the yeast-distribution is that of ro cells per unit volume of $\frac{1}{400} \mathrm{c}$.mm., corresponding to $4 \times 10^{\theta}$ cells per 100 c.c. This number of cells weighs, on an average, $1 \mathrm{grm} .{ }^{1}$

If, in any such given case, we take $M$ to denote the weight of maltose fermented per 100 c.c. per gramme of yeast (Io cells per unit volume) per: hour; $c$ the calories liberated by the fermentation of I $\mathrm{grm}$. of maltose; and $s$ the specific heat of the yeast-cell, which may be taken as approxi-' mately 0.86 ; then, assuming all conditions constant, the potential increase of temperature of the cell, if all the liberated energy of metabolism were retained in it, is represented by $\frac{M c}{s}$.

In the following Table is given a summary of the resuits of ten experiments, from which have been calculated in the last two columns the time required for a yeast-cell under stated conditions of temperature to ferment.

1 This can be shown by washing a freshly coltivated yeast with water and then freeing it as far as possible from adhering moisture, either by repeated pressing between folds of filter paper or by. distributing it over the surface of a porous tile. When one gramme of a top-fermentation yeast so prepared is thoroughly mixed with water and made up to 100 c.c. the cell-count per unit volume of a of c.mm. varies very little from ten. 
its own weight of maltose, and also the potential rise of temperature of the cell per hour, if all the heat due to metabolism had been retained.

The values are not strictly comparable, owing to the fermentations having been made at different times, and in some cases with different yeasts. It will be noticed that between about $14^{\circ}$ and $16^{\circ} \mathrm{C}$. the time required for a yeast-cell to ferment its own weight of sugar varies from about $8 \frac{1}{2}$ to $9 \frac{1}{2}$ hours, and that the heat generated during one hour is sufficient to raise the temperature of the cell by $15^{\circ}$ or $16^{\circ} \mathrm{C}$.

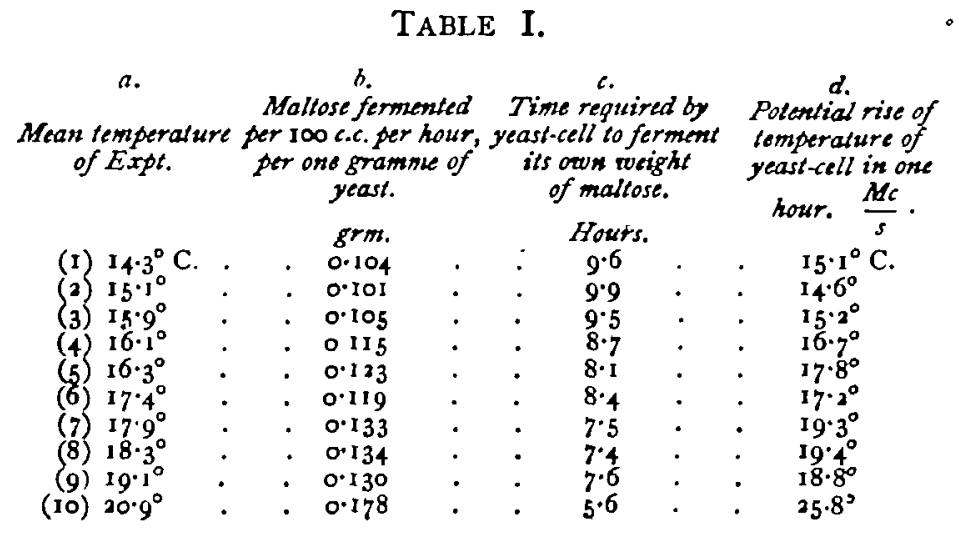

Although the entire range of temperature in these experiments is only about $6^{\circ} \mathrm{C}$., the influence of increasing temperature on cell-metabolism is consistently shown throughout, and the results are such as to indicate a high 'temperature coefficient' for yeast.

During the course of his studies on alcoholic fermentation, A. Slator has introduced a new experimental method which in his hands has given, and is still giving, results of the greatest possible interest as regards the mechanics of fermentation (Journ. Chem. Soc., Trans., 1906, p. 128; ibid., I 908 , p. 217). It consists essentially of measuring the fermentative change over a brief interval of time by change of manometric pressure due to the evolution of $\mathrm{CO}_{2}$. By making the time intervals very short, various disturbing causes, such as changes of concentration, alteration in the activity or amount of the yeast, and the accumulation of the products, are reduced to a minimum.

Slator was thus able to prove satisfactorily that, other things being the same, the rate of fermentation of a sugar is proportional to the number of active cells in a given volume, i. e. to the 'density of the population'; and that the rate is almost independent of the concentration of the sugar except in very dilute solutions.

With this same apparatus, Slator also investigated the influence of temperature on the rate of fermentation, and for the first time obtained 
a satisfactory series of values for the temperature-coefficients over a range from $5^{\circ} \mathrm{C}$. to $35^{\circ} \mathrm{C}$.

The coefficients are large, but diminish with increasing temperature: for instance, a rise of temperature from $5^{\circ} \mathrm{C}$. to $10^{\circ} \mathrm{C}$. results in the fermentation at the higher point being 2.65 times as rapid as at the lower; whereas raising the temperature from $30^{\circ} \mathrm{C}$. to $35^{\circ} \mathrm{C}$. results in an increased rapidity of only I.35 times. He also found that these coefficients are remarkably similar for brewery yeasts, distillery yeasts, and wine yeasts, so much so in fact that he was led to regard the temperature-coefficient as characterizing certain constant properties of the enzyme symase, which is common to all alcoholic yeasts.

The following Table gives the temperature coefficients, as determined by Slator, for brewery yeasts (top fermentation); they are expressed as quotients for $5^{\circ} \mathrm{C}$. :

\section{TABLE II.}

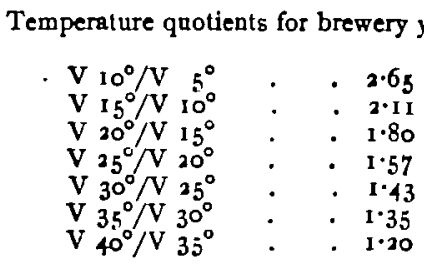

By making use of the above Table of temperature coefficients, taken from Slator's paper, and expressing as unity the amount of sugar fermented in a brief interval of time at $5^{\circ} \mathrm{C}$. through the agency of a definite number of yeast-cells per unit volume, we can obtain a series of values which represent the progressive rates of fermentation expressed as a function of the temperature between $5^{\circ}$ and $40^{\circ} \mathrm{C}$. The values which $\mathrm{I}$ have recast in this way are given in Table III, and are also represented graphically in the curve of Fig. 8.

\section{TABLE III.}

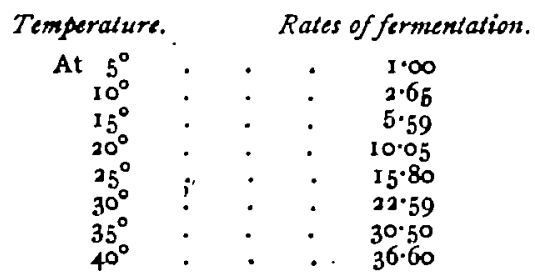

Since this curve (Fig. 8) is based on true temperature coefficients, we can ascertain by means of its use the effect which any given rise of tem- 
perature would have on the rate of fermentation where the data have been previously obtained at any lower temperature. It can, for instance, be applied to any of the experiments recorded in Table I. Only one or two examples are necessary.

In the first experiment, recorded in Table I, in which the mean temperature of fermentation was $14.3^{\circ} \mathrm{C}$., it was found that the maltose which was fermented per 100 c.c. per hour by $\dot{I}$ grm, of yeast (Io cells per unit volume) amounted to $0.104 \mathrm{grm}$. Let us see what the amount of maltose fermented would have been under precisely the same conditions if the temperature had been raised to $30^{\circ}$ and $40^{\circ} \mathrm{C}$. respectively; and how this would have affected $(a)$ the time reguired for a veast-cell to ferment its own weight

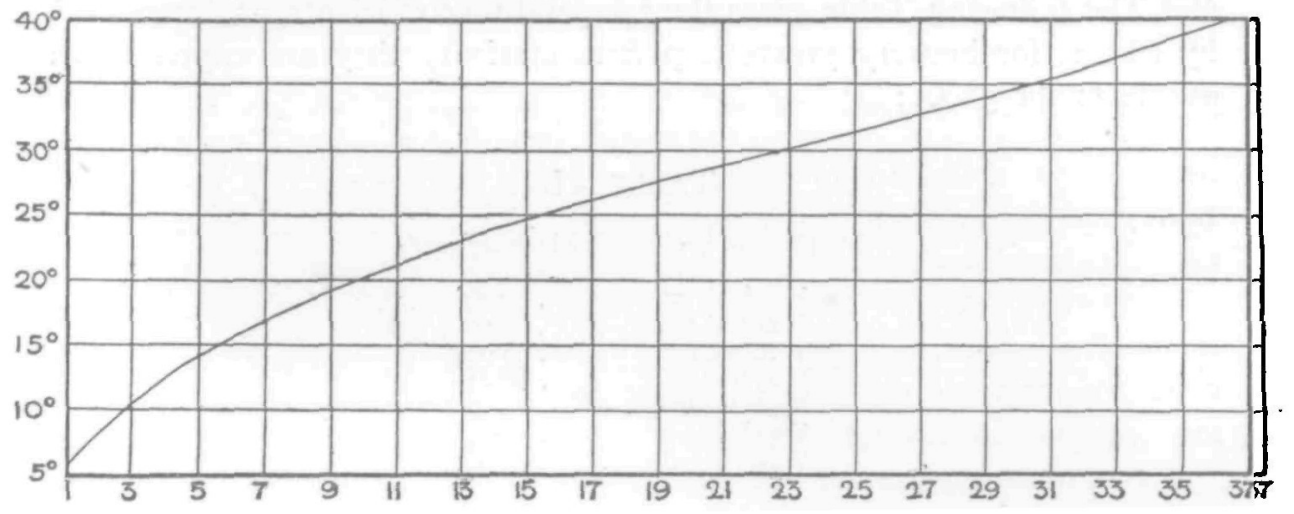

FIG. 8. Graphical representation of Table III, showing influence of temperatare on fermentations. Amount of sugar fermented at $50^{\circ} \mathrm{C}$. is taken as unity. Dednced from A. Slator's temperatare coefficients for brewery yeast. See Table II.

of the sugar, and $(b)$ the potential rise of temperature of the cell under adiabatic conditions.

On reference to the curve, we note in the first place that the ordinate of temperature corresponding to $14 \cdot 3^{\circ} \mathrm{C}$. cuts the curve at the co-ordinate $5^{2} 2$, and that the ordinate corresponding to a temperature of $30^{\circ}$ intersects the curve at 22.6 . The amount of maltose fermented at $30^{\circ}$ will therefore be $\frac{22.6 \times 0.104}{5.2}=0.45^{1} \mathrm{grm}$. per 100 c.c. per I grm. of yeast per hour; $\therefore$ the time taken for the yeast to ferment its own weight of maltose at $30^{\circ}$ will be $\frac{I}{0.45 \mathrm{I}}=2.2$ hours, and the potential rise of temperature of the yeastcell in one hour under these new conditions will be $\frac{0.45^{\mathrm{I}} \times 125}{0.86}=75.5^{\circ} \mathrm{C}$, instead of $15.1^{\circ} \mathrm{C}$.

In the same manner it can be shown that at $40^{\circ} \mathrm{C}$. the amount of sugar fermented per hour, per 100 c.c. per I grm. of yeast, would be still further raised to $0.73^{1} \mathrm{grm}$., whilst the time occupied by a cell in fermenting its 
own weight of sugar under these conditions would be only $\mathrm{I} \cdot 3$ hours, and the potential adiabatic rise of temperature of the cell would be in one hour I06. $2^{\circ} \mathrm{C} .{ }^{1}$

Considerations of this kind bring home to us in a striking manner the intense nature of the metabolic processes which go on in a yeast-cell, and the large liberation of apparently wasted energy which accompanies them. It may be permissible for a moment to compare a yeast-cell in this respect with the human body. I am informed by Dr. Leonard Hill that the metabolism of a man quietly resting in bed can be taken as resulting in the production of 2,000 large calories per diem, or 83.3 large calories per hour. Assuming a body-weight of 65 kilograms, and a mean specific heat of 0.83 , and further supposing the metabolism to continue at the same rate, then the heat evolved would be sufficient to raise the body-temperature of the man at the rate of about $\mathrm{I} \cdot 5^{\circ} \mathrm{C}$. per hour.

But, as we have just seen, the metabolism of a yeast-cell at about the temperature of the human body evolves heat sufficiently fast to raise its body-temperature $106^{\circ} \mathrm{C}$. per hour, or about seventy times as fast as in the case of a man at rest.

We may now ask, what is the physiological significance of this enormous metabolism and liberation of energy which the yeast-cell exhibits in pursuance of its life-functions, and which seem so disproportionate to its requirements for reproduction and nutrition?

Are we to regard the phenomena as being to some extent accidental, and due to the fact that the living cell requires some small but essential part of the sugar molecule, the removal of which brings about a rearrangement of the residual portions of the molecule with consequent transformation of potential into kinetic energy? According to this view, the action of the yeast may be likened to the removal of the keystone of an arch and the partial demolition of an edifice.

This was substantially the explanation given by Pasteur many years ago. He regarded the reproductivity of the yeast-cell and its fermentative power as being correlative but inverse phenomena.

By a somewhat curious misinterpretation of experimental results, Pasteur believed he had evidence that when the yeast-cell was fully supplied with oxygen, and was therefore reproducing itself freely, its faculty for fermenting sugar was at a minimum, or even altogether in abeyance. On the other hand, its fermentative power was supposed to be at a maximum under anaerobic conditions, this being due to the yeast then taking the requisite oxygen from the sugar, thus destroying the sugar molecule as such.

1 It is not without interest to compare the energy liberated under these conditiong in the yeastcell with that erolved by the atomic disintegration of radium, which is said to produce sufficient heat to raise its own weight of water through $100^{\circ} \mathrm{C}$. per hour. 
That this was a wrong interpretation of the facts was conclusively shown by Adrian Brown (Journ. Chem. Soc., Trans., I892, p. 6I ; ibid., I 894, I9II), who has brought forward unmistakable evidence, proving that yeast well supplied with free oxygen possesses as much or even more fermentative power than the same yeast under conditions of oxygen starvation; and more recently this has been confirmed by A. Slator. But the errors of great men live long after them, and it will no doubt require another generation of workers to eliminate the statement from the text-books. ${ }^{1}$

Whatever truth there may be in the view that the breaking down of the sugar molecule, and the resulting liberation of energy, is due to the cell protoplasm abstracting and appropriating some small constituent part of the sugar molecule, this hypothesis receives no support from the conjoint study of the reproductive and fermentative functions of the cell, which are certainly not inversely related to each other.

It will help us if we consider for a moment the behaviour of a yeastcell bathed in a suitable nutrient liquid, at a time when the free oxygen originally dissolved in the liquid has been completely absorbed by the yeast, and when the 'oxygen charge' of the cells has completely spent itself in several succêssive generations of subdivision. As we have seen in Part I of this paper, no further reproduction is possible under these conditions, if access of oxygen from without is prevented, but the cells speedily acquire a static condition of equilibrium with regard to the medium, and this condition remains constant for some time. During this period it can be experimentally demonstrated that the average mass and composition of the cells remain constant; in other words, regarded from the point of view merely of cell-maintenance, the normal katabolic and anabolic processes, if they still exist at all, must just balance each other, and little or no further extraneous supply of energy is required to continue the life of a cell so placed. Notwithstanding this, we find under these apparently static conditions of maintenance an enormous activity in the metabolic ' mill', through which continues to pass an amount of substance which, under certain conditions of temperature, may amount to several times the mass of the cell in a few hours, and a corresponding liberation of energy sufficient to raise the cell-temperature to a very high point.

It may be argued that this apparent waste of energy is due to the necessity of the yeast-cell having to share its temperature with the surrounding medium, which is one of high specific heat, but under any circumstances it is difficult to see how any rise of temperature in the medium can be of any use to the cell under the above conditions, since such a rise can only stimulate the 'mill' to a further output of work which appears to be

1 Quite recently I have heard of a proposed improvement in wine-making which was entirely based on this fundamental error of assuming the inverse relation of the reproductive and fermentative faculties of yeast. 
perfectly useless for the economics of the cell, and immensely disproportionate to any 'toll' which the mill requires to keep it in working order.

The explanation of this apparent paradox appears to lie in the fact that the conditions under which we generally cultivate yeast, that is to say, in comparatively large masses of liquid containing but a very limited supply of oxygen, are eminently artificial. They have been imposed by the exigencies of industries in which the fermentative faculty of the yeast-cells has been purposely enhanced, whilst the reproductive faculties have been restricted. These artificial conditions differ in toto coelo from the natural conditions under which the specific physiological characters of the Saccharomycetes have been evolved. If we wish to study the question in a philosophical manner, it is to the vineyard and orchard we must have recourse, rather than to the vats of the wine-maker, the brewer, and distiller.

The natural habitat of the various forms of yeasts is the outer skin of fruits, and especially those succulent fruits which contain abundance of sugar when ripe. ${ }^{1}$ They may, for instance, be detected somewhat sparsely scattered over the skin of a ripe grape, awaiting their opportunity of gaining access to the stores of nutrient material from which they are separated by a thin semi-permeable membrane. This opportunity arises the moment the skin of the grape is ruptured, and such a rupture may be brought about by a variety of natural causes, such as the undue swelling of the ripe fruit after rain, the attack of birds, insects, or fungi, or by the accidental crushing of the berry by the foot of a passing animal.

The extraneous yeasts and their ascospores now find themselves in a medium rich in all the nutrient substances they require, and one to which atmospheric oxygen can gain ready and continuous access, owing to the small scale of the natural operations.

Hence, as one may readily see in the vineyard at vintage time, extremely rapid cell-multiplication takes place, which has not the same check imposed upon it as it has when the cultivations are made on a large scale in the wine-makers' vats. This rapid and constant building up of new cells, under the continued action of oxygen, requires a constant source of extraneous energy, which is furnished by the ancillary fermentative function of the cells. Moreover, since the cell-growth is going on in a medium of high specific heat, and under conditions in which there is a natural tendency for rapid equalization of temperature with the surroundings, it is manifestly to the advantage of the organism to have some other and more intense source of energy than that supplied by the respiratory processes. By a study of these natural cases, it becomes easier to understand the true

1 The origin of the wine-geasts is obvious. That of the various races of brewers' yeast is not known with certainty, any more than the origin of some of our domestic animals and cereals. 
relation of the fermentative to the reproductive processes, and why the yeasts have acquired their fermentative power.

It is but a special instance of a well-established generalization or 'law' of nature, that the mechanism of every living organism is adjusted to the one great aim and object of reproduction.

That we can by means more or less artificial keep the reproductive power of a yeast in abeyance, whilst still availing ourselves of its fermentative power, has hitherto obscured the relation of the two functions, and hence has given rise to the somewhat exaggerated idea of the purposeless and prodigal waste of the yeast-cell regarded as a living unit.

\section{Addendum.}

It follows from the above considerations that, if we could devise means for measuring with exactness the amount of heat evolved during the disappearance of I $\mathrm{grm}$. of sugar under the influence of yeast, whilst the cells are in process of active reproduction, this amount of heat ought to fall short of that produced by the fermentation of the same amount of sugar when there has been no yeast reproduction, the difference being due to the energy required for the observed yeast reproduction.

I have not succeeded hitherto in obtaining numerical results which can be relied upon as giving the 'heat of formation' of yeast, but in those cases where yeast reproduction was still in progress within the observed timeintervals, I have generally found distinctly less evolution of heat per unit weight of sugar destroyed than where the cell-reproduction had ceased.

In one case, for instance, in which the fermentation of a malt-wort had been continued for $6 \frac{1}{2}$ hours, the maltose which had disappeared per hour was $0.117 \mathrm{grm}$. per 100 c.c., and the yeast increase per hour was I.26 cells per unit volume, equivalent to $0.126 \mathrm{grm}$. per $100 \mathrm{c.c}$. of moist yeast, or $0.027 \mathrm{grm}$. of dry yeast. The ratio of the sugar used up, to the $d r y$ yeast formed, therefore had the high value of $I: 0.23$.

The heat developed per gramme of sugar fermented in this case amounted only to 114.4 calories, instead of 125 , the normal value. 